\section{Nastamonu Eğitim Dergisi Kastamonu Education Journal}

Temmuz 2019 Cilt:27 Sayı:4

kefdergi.kastamonu.edu.tr
Başvuru Tarihi/Received: 17.03 .2018

Kabul Tarihi/Accepted: 10.10 .2018

DOI: $10.24106 /$ kefdergi.2828

\title{
Öğretmen Adayı Bilgi ve İletişim Teknolojisi Yeterlikleri Ölçeğinin Türkçe'ye Uyarlanması
}

\section{Adaptation of Information and Communication Technology Competency Scale to Turkish for Pre-Service Teachers}

\section{Öz}

\author{
Şahin GÖKÇEARSLAN ${ }^{1}$, Tuğra KARADEMIR COŞKUN² ${ }^{2}$ Sami ŞAHIN ${ }^{3}$
}

Bu araştırmada, Tondeur ve diğerleri (2017) tarafindan geliştirilen öğretmen adaylarına yönelik "Bilgi ve illetişim Teknolojisi Yeterlikleri Ölçeği'nin" Türkçe uyarlaması amaçlanmış ve psikometrik analizleri gerçekleştirilmiştir. Doğrulayııı faktör analizi ve psikometrik analizler 331 öğretmen adayı üzerinde yürütülmüştür. Doğrulayıcı faktör analizi sonucunda ölçeğin 2 boyutlu modelinin Türk kültürüne uygun olduğu belirlenmiştir. Ölçek, 9 maddesi öğretmen adayının öğrencilerin bilişim teknolojilerini kullanımını destekleme, 7 maddesi ise bilişim teknolojilerini öğretim tasarımında kullanma öz yeterliği algısını ölçmek üzere iki faktör altında toplanmıştır. Ölçeğin iç tutarlılığını gösteren Cronbach Alfa katsayısı ölçeğin bütünü için 0.944 'tür. Buradan hareketle, ölçek öğretmen adaylarının bilgi ve iletişim teknoloji yeterliklerini ölçmede kullanılmak üzere güvenilir ve geçerli bulunmuştur. Ayrıca, yapılan psikometrik analizler göre de öğretmen adaylarının BiT yeterlik düzeylerinin yüksek olduğu, cinsiyet, sınıf ve yaş düzeyinin bu sonuçlar üzerinde anlamlı bir etkisinin olmadığı bulunmuştur.

Anahtar kelimeler: Öğretmen adayı, bilgi ve iletişim teknolojisi, yeterlik, ölçek uyarlama

\section{Abstract}

In this study, Turkish adaptation of information and communication technology competency scale developed by Tondeur et al. (2017) was purposed and psychometric analysis was performed. Confirmatory factor and psychometric analysis were conducted on 331 prospective teachers. Confirmatory factor analysis' result shows that scale's original 2-dimensional models were appropriate for the Turkish sample. At the end of the analysis, similar to the original scale, the scale was confirmed at two factors as ICT competencies to support pupils for ICT use, ICT competencies for instructional design, and a significant and high $(p<0.001)$ correlation between factors was found. The Cronbach's alpha coefficient, which indicates the internal consistency of the scale, was found 0.944 for the whole scale. Starting from this point, the scale is considered as a reliable and valid instrument in terms of measuring pre-service teachers' information and communication technology competency. Besides, according to psychometric analysis, it has also been found that the ICT proficiency levels of the pre-service teachers are high and no significant difference was found between ICT competency and gender, class and age level.

Keywords: Pre-service teacher, information and communication technology, competence, scale adaptation

1. Gazi Üniversitesi, Enformatik Bölümü, Ankara, Türkiye;https://orcid.org/0000-0003-3532-4251

2. Sinop Üniversitesi, Eğitim Fakültesi, Bilgisayar ve Öğretim Teknolojileri Eğitimi, Sinop, Türkiye; https://orcid.org/0000-0003-4295-24040

3. Gazi Üniversitesi, Gazi Eğitim Fakültesi, Bilgisayar ve Öğretim Teknolojileri Eğitimi, Ankara, Türkiye; https://orcid.org/0000-0003-1873-5243

Atıf / Citation: Gökçearslan, Ş., Karademir Coşkun, T., \& Şahin, S. (2019). Öğretmen adayı bilgi ve iletişim teknolojisi yeterlikleri ölçeğinin Türkçe'ye uyarlanması. Kastamonu Education Journal, 27(4), 1435-1444. doi:10.24106/kefdergi.2828 


\section{Extended Abstract}

Introduction: Depending upon 21. century students' competency changing rapidly, teachers' competency has been changing and it is clear that Information and Communication Technology (ICT) has an important position in these competencies. Besides, some international organizations also emphasize the importance of ICT in education. Different scales to measure of pre-service teachers' ICT competency take place in the literature and ICT competencies are considered from different angles in this studies. When the literature is reviewed, it is seen that there is only one scale, which measures of preservice teachers' ICT competency. The scale, which adopted in this study has two dimensions as 21 . century competencies and instructional design and thus the scale adapted differ from other scales in that sense.

Tondeur et al. (2017) have developed a self-assessment scale for teacher candidates to determine their competence perceptions of ICT use in education. The scale was created by considering ICT competency framework (ICTC-CF) which was developed by the Expertise NetWork at the Ghent University Association and include three significant domains in the teaching profession: instructional and pedagogical tasks, professional development and the school in a broader context. In the process of the scale development, comprehensive literature review has been conducted by receiving professional help from experts and it has been utilized competency definitions of international organizations (UNESCO, Common Europan Framework, Digital European Like Literacy, Tondeur et al., 2017, p. 472) and countries (such as UK, China, America, Belgium). Tondeur et al. (2017) have collected data from 931 teacher candidates to develop the scale. The first sub-sample was utilized for exploratory factor analysis, and the second was used for confirmatory factor analysis for testing whether the construct was verified. As a result of the validity studies, the scale was verified in two constructs as 'sufficiency to support students for ICT use' and 'ICT use qualifications for instructional design '. At the end of all the studies, the "Teacher Candidate Information and Communication Technology Proficiency" scale consisting of 19 items and two factors were revealed.

Purpose: In this study, the scale mentioned above was adapted and then the scale adapted was conducted to teacher candidates so as to compare with various variables.

Method: Data was collected from 331 participants who study at Faculty of Education, Turkey. 242 of participants are women and 89 is the man. Their age range from 20 to 25 and the skewness is within the normality limits of 0.29 and pause (-1.26) (George \& Mallery, 2010; Gravetter \& Wallnau, 2014).

The steps which are given below followed by the scale's linguistic equivalence.

- The scales were translated into Turkish by experts $(n=5)$ who are well versed in English language, familiar with both cultures and two experts in the field of ICT integration in education. As a result of the separate work of the experts, the differences have been discussed and solved.

- The scale translated was sent a Turkish language expert so as to make grammar and content integrity control, and the scale was edited with regard to expert's suggestions.

- The scale translated Turkish was translated English once more by the expert who has a command of two languages and scales original version and translated version were compared.

- The scale was applied 15 pre-service students to determine whether the scale was apparentness and it is understood that it is an ineligible scale for the target group.

Data Analysis: Confirmatory factor analysis was performed via SPSS AMOS 22 software. Before analysis, the data was controlled to determine whether the data has normal distributions, and it is determined that the data has the normal distribution. For descriptive findings, participants' mean scores for each factor were controlled. In addition to descriptive findings, gender, and class level were analyzed with one-way ANOVA to determine whether there was an effect on the outcome.

Findigs: When the standardized results of the DFA are examined, it is determined that similar to the original measure, the scale was confirmed by two factors as ICT competencies to support pupils for ICT use (ICTC-SP), ICT competencies for instructional design (ICTC-ID), and A high and significant $(p<0.001)$ correlation between factors was found. On the other hand, regression coefficients of the items show that they vary between 0.58 and 0.85 , and all of them are significant $(p<0.001)$. After three items were extracted from the scale, it is realized the scale has high fit indices. (CMIN/DF $=2.445, N F I=0.921$, $\mathrm{RFI}=0.907, \mathrm{CFI}=0.952, \mathrm{RMSEA}=0.066$ ).

In order to evaluate the internal consistency of the factors, the Cronbach alpha coefficient was calculated for each factor by using SPSS 22 software and it is found 0.919 for the ICTC-ID and 0.884 for the ICTC-SP. Reliability co-efficiency of the factors were also confirmed by calculating the mixed reliability coefficient ( 0.921 for ICTC-SP and 0.873 for ICTC-ID).

When the descriptive findings are examined, the general average for ICTC-SP is 3.93 in females and 3.91 in males, but the difference was not significant $(F=0.026 ; p>0.05)$. ICT-SP general average for the undergraduate students is 3.96 and the participants in the pedagogical formation certificate programme are 3.88 , but this difference was not significant $(F=1.00$; $\mathrm{p}>0.05$ ). On the other hand, ICTC-ID for all groups - female/male, undergraduate students/pedagogical formation certificate programme students is 3.90. Accordingly, it is clear that participants in all groups have the same competency level by ICTCID. On the other hand, differentiation on participants' age distribution according to ICTC-SP and ICTC-ID was calculated with Pearson and the significant association wasn't observed (for ICTC-SP: $r=0.056, p>0.05$, and ICTC-ID $=0.061, p>0.05$ ).

In this study, Information and Communication Technology Competency Scale was adapted to Turkish culture and then was applied to the pre-service teacher so as to compare with different variables. In the future research, the effects of the teacher-trained ICT competencies on the student-related characteristics and the learning processes in instructional design in teacher education can be investigated. It can also be used for teacher self-assessment. Work on individual and contextual factors (Almerich, Orellana, Suárez-Rodríguez, \& Díaz-García, 2016) where ICT competencies could be conducted. 


\section{Giriş}

21. yüzyılın değişen ihtiyaçları ve hızla gelişen teknolojiler, öğrenen ve öğreten yeterliklerinde değişikliklere neden olmaktadır. Bu değişimin izlerini çeşitli kuruluş, hükümet ya da akademik çalışmalar bünyesinde tanımlanan 21. yüzyıl birey yeterliklerinde görmek mümkündür. Amerika Birleşik Devletleri'nden 33 kurumun desteği ile 21 eyalette uygulanan ve bir eğitim projesi olan "21. Yüzyıl Öğrenme Ortaklığı/Partnership for 21st Century Learning (P21)" adlı proje (P21, 2016), bu değişimin önde yer alan projelerindendir. Proje kapsamında 21. yüzyıl yeterliklerinin dört ana ve 16 alt başlıkta tanımlandığı görülmektedir. Bu yeterlik başlıkları “öğrenme ve yenilik becerileri” ana başlığı altnnda eleştirel düşünme ve problem çözme, yaratıcı düşünme ve yeniliği uygulama, iletişim ve işbirliği becerilerini kapsamakta, "yaşam ve kariyer becerileri" ana başlığı altında esneklik ve uyum, girişimcilik ve öz-yönelim, sosyal ve kültürler arası beceriler, üretkenlik ve mesuliyet ile liderlik ve sorumluluk alt başıkları yer almaktadır. Diğer bir ana başlık olan "bilgi ve iletişim teknolojileri becerileri" başlı̆ı altında ise 21. yüzyıl bireylerinin bilgi, medya ve iletişim okuryazarı alt başlıklarına işaret edilmiştir. Ayrıca proje "temel konular ve 21. yüzyıl temaları" ana başlı̆ı altında okullarda öğretim programlarında yer alması gereken temel konuları ingilizce, dil sanatları, dünya dilleri, sanat, matematik, ekonomi, bilim, coğrafya, tarih, yönetim ve yurttaşlık olarak tanımlarken, 21. yüzyıl disiplinler arası temel konuları ise küresel farkındalık, finansal, ekonomik, iş ve girişimcilik okuryazarlığı, sivil okuryazarlı̆̆ı, sağlık okuryazarlığı ve çevre okuryazarlığı olarak belirtmektedir. Benzer şekilde, 21. Yüzyıl Becerilerinin Değerlendirilmesi ve Öğretimi projesi (The Assessment and Teaching of 21st Century Skills-ATC 21) Cisco, Intel ve Microsoft firmalarının ortaklı̆ında aralarında Finlandiya, Portekiz ve İngiltere gibi ülkelerin yer aldığı alt farklı ülkenin ortaklığı ile gerçekleştirilmiş ve projede dört ana başlıkta 21. yüzyıl becerileri tanımlanmıştır (Binkley ve diğerleri, 2012). Projeye göre 21. yüzyıl becerileri "Düşünme yolları" ana başlığı altında yaratıcılık ve yenilik, eleştirel düşünme, problem çözme ve karar verme, öğrenmeyi öğrenme ve üst biliş; "çalışma yolları" ana başlığı altında iletişim, işbirliği; "çalışma araçları" ana başlığı altında bilgi okuryazarlığı ve Bilgi ve iletişim Teknolojileri (ВіT) okuryazarlığı; "dünyada yaşamak" ana başlığı altında vatandaşlık, yaşam ve kariyer, kişisel ve sosyal sorumluluklar ile kültürel yeterlik ve farkındalıktır. Wagner'in (2008) yaptığı bir çalışmada ise 21 yüzyıl yeterliklerinin merak ve hayal gücü, eleştirel düşünme ve problem çözme becerileri, işbirliği ve liderlik, uyum, girişimcilik, etkili konuşma ve yazma becerileri, bilgiye ulaşma ve analiz etme olarak kategorize edilebileceği belirtilmektedir. Keane ve Keane (2013) ise 21. yüzyıl yeterliklerini yaratıcılık, iletişim, eleştirel düşünme ve teknolojinin üretici kullanıılları olarak dört ana temaya ayırdığı görülmektedir.

Amerika Ulusal Araşttrma Enstitüsü (NRC, 2011) ise 21. yüzyıl becerilerini bilişsel alan, içsel zeka alanı ve kişilerarası alan olarak sınıflandırmaktadır. Bilişsel alan düşünme ve akıl yürütme ile ilgili becerileri kapsarken, içsel zeka alanı, bireyin davranış ve duygularını hedeflere ulaşmak için düzenleme becerisini içermektedir. Kişilerarası alan ise diğer kişilere bilgi aktarma ile beraber mesajlarını anlama ve yorumlamayı içerir. Bir bütün olarak 21. yüzyıl beceri tanımları değerlendirildiğinde eleştirel düşünme, yaratıcı düşünme, problem çözme gibi üst bilişsel yeterliklerin en çok tekrarlanan temalar arasında olduğu bu temaları yenilik, inovasyon, bilgi okuryazarlı̆ı ve bilgi ve iletişim teknolojileri okuryazarlığının izlediği görülmektedir. Buradan yola çıkılarak 21. yüzyıl öğrencisinden beklenenin ezber bilgiyi alan ve tüketenden ziyade, yaratıcı, meraklı, keşfetmeye ve üretmeye hazır, bilgi ve iletişim teknolojileri konusunda okur-yazar, lider, girişimci ve yönlendirici olan kişi olma olduğu söylenebilir (Karademir, 2018).

21. yüzyıl becerilerindeki değişim zaman içerisinde eğitim alanını etkilemeye başlamıştr. Fadel ve diğerleri (2015) değişen iş gücü ve 21. yüzyıl yeterliklerine bağlı olarak 21. yüzyıl okullarının dört yeni boyutta yapılandırılması gerekliliğini belirtmektedirler. Bu boyutlar bilgi (teknoloji ve mühendislik, biyoenerji, medya, girişimcilik ve iş geliştirme, kişisel finans, sağlık, sosyal sistem), beceriler (yaratıcılık, eleştiril düşünme, iletişim, işbirliği ), karakter (farkındalık, merak, cesaret, direnç, etik, liderlik) ve biliş üstüdür (öz-yönlendirme ve öğrenmeyi öğrenme). Bu değişimin yansımalarını çeşitli hükümetlerin gerçekleştirdiği eğitim temalı adımlarda da görmemiz mümkündür. Japonya (2006) 'Zest for Living' adı verilen eğitim reformu ile yeterlikler arasına deneyimleme, problemi fark etme ve çözümleme temalarını eklerken benzer şekilde Finlandiya (2010) yaratıcı düşünme, problem çözme, kendini ifade edebilme, katılım, girişimcilik, öz-farkındalık ve sorumluluk alma becerilerini eklemiştir. Singapur (2010) öğrencilerine küresel firsatların avantajından yararlanabilecekleri daha iyi firsatlar sunmak için 21. Yüzyıl Yeterlilikleri ve Öğrenci Çıktıları için Yeni Çerçeve (New Framework for 21st Century Competencies and Student Outcomes) planını hazırlamış ve 21. yüzyıl ana becerilerini değerler, sosyal ve duygusal yeterlikler, yeni ortaya çıkan küresel becerileri ise vatandaşlık okuryazarlığı, küresel farkındalık ve kültürler arası beceriler, eleştirel ve yaratıcı düşünme, iletişim, işbirliği ve bilgi becerileri olarak sınıflamıştır. Kanada ise günümüz becerilerini üç ana kategoride aktarmaktadır. Bunlar genel 21. yüzyıl becerileri (merhametli, aktif katılımlı, yurttaş, eleştirel düşünen, hayal eden, esnek çalışma alışkanlıkları olan) ve asıl becerilerdir (okuma, yazma, dokümantasyon, bilgisayar kullanımı, sözel iletişim matematiksel düşünme, düşünebilme becerileri) (Saavedra ve Opfer, 2012). Ayrıca, Kereluik ve diğerlerinin (2013) yaptıkları bir derleme çalışmasında on beş farklı kitap, rapor ve araştırma incelenmiş ve 
bu çalışmalarda geçen 21. yüzyıl öğrenmeleri ortak temalar altında toplanmıştır. Tüm çalışmaların analiz edilmesi sonucunda 21 yüzyıl öğrenmesinin temel bilgiler (temel içerik bilgisi, çapraz disiplin bilgisi ve dijital ve BiT okuryazarlığı), değişim bilgileri (yaratıcılık ve inovasyon, yaratıcı ve eleştirel düşünme, iletişim ve işbirliği), insancıl bilgiler (iş/meslek becerileri, kültürel yeterlik, etik ve duygusal farkındalık) ana başlıkları altında toplandığı belirlenmiştir.

Alan yazın incelendiğinde değişimin izlerinin sadece öğrenci ve okul kapsamında kalmadığı öğretmen yeterliklerindeki değişimi de tetiklediği görülmektedir. Çünkü 21. yüzyıl becerilerinin kazandırılması için öğretmenlerin teknoloji kullanımına yönelik yeterliklerinin de geliştirilmesi önem taşımaktadır (TED, 2009; Vo ve Nyugen, 2010 aktaran: Durak ve Seferoğlu, 2017). Bu önemin vurgusunu uluslararası kuruluşların revize ettikleri 21. yüzyıl öğretmen yeterliklerinde görülmektedir. Uluslararası alanda önemli bir organizasyon olan International Society for Technology in Education (ISTE) hem 2009 yılında hem de 2017 yılında eğitici yeterliklerinde güncellemeye gitmiştir. Günümüz eğitimcileri için öğrenen, lider, vatandaş, işbirlikçi, tasarımcı, kolaylaştırıcı ve çözümleyici olmak üzere yedi farklı alanda ana yeterlik başlıkları tanımlamıştır. Bu yedi farklı ana yeterlik tanımları incelendiğinde ise görülmektedir ki teknoloji ile yönetme, teknoloji ile öğrenme, dijital dünyaya hazırlama, teknolojik işbirliğini tetikleme ve teknoloji ile firsat sağlama ile ilgili yeterliklerin sıklıkla belirtildiği görülmektedir. Özellikle tasarımcı olma yeterliği altında günümüz eğitimcilerinin teknolojiyi kullanan, adapte eden, kişiselleştiren ve tasarım yapan bireyler olması gerekliliği dile getirilmektedir (ISTE, 2017).

UNESCO'nun (2011) yayınladığı öğretmen yeterlikleri incelendiğinde BiT'in tüm branş öğretmenleri için önemli olduğu vurgusu öne çıkmaktadır. Öğretmenlerden temel donanım ve yazılım becerilerinin yanı sıra, verimlilik uygulamaları, web, iletişim ve sunum yazııımları ile yönetim uygulamalarını da kullanması beklenmektedir. Bununla beraber öğretmenlerden BiT ile zenginleştirilmiş öğrenme ortamlarını ve yenilikleri okullarına adapte etmek için eğitici ve lider olma anlayışına sahip olması, ayrıca mesleki gelişimine destek sağlayacak pedagojik bilgi edinme için teknolojiyi kullanma bilgi ve becerisine de sahip olmaları beklenmektedir. Benzer biçimde 21. yüzyıl öğretmenlerinin Biт becerilerine sahip olmalarının yanında bu becerileri içerik ve pedagoji ile birleştirerek sınıf ortamlarına aktarmalarının önemini belirten çalışmalara rastlanmaktadır (Mishra ve Kohler, 2006; Tonduer ve diğerleri, 2012). Dolayısıyla, özellikle öğretmen yetiştiren kurumların 21. yüzyıl becerilerine sahip eğiticiler yetiştirmelerine yönelik önem gün geçtikçe artmaktadır (Sang, Valcke, Van Braak ve Tondeur, 2010). 21. yüzyıla uygun öğretmenlerin yetişmesinden eğitim fakülteleri sorumludur (Göksun ve Kurt, 2017) ve eğitim fakültelerinde verilen teknoloji eğitimleri büyük önem taşımaktadır. Tonduer ve diğerlerine (2012) göre öğretmen adaylarının mutlaka teknolojinin sınıflarda kullanımı konusunda pedagojik süreçleri içeren bir eğitime sahip olmaları gerekir. Öğretmenlerin öğrencilerin performansı üzerinde etkilerinin büyük önem taşıdığı (Gibson ve Dembo, 1984 aktaran Tokmak, Konokman ve Yelken, 2013) düşünüldüğünde öğretmen adaylarının teknoloji yeterlikleri ve sınıf içinde teknolojiyi kullanabilme becerileri ilerleyen dönemlerde öğrencilere aktaracakları bir yeterlik halini almaktadır. Teknoloji kullanma yeterliğine sahip olarak sınıf ortamına gelen öğretmen adayı öğrencilerine teknoloji yeterliği kazandırma konusunda daha başarılı olabilir. Öğretmen adaylarının teknolojinin entegrasyonu konusundaki öz-yeterlik inançlarının onların gelecekte başarılı uygulamalar gerçekleştirme konusu ile iliş̧i olduğunu görülmektedir (Anderson, Groulx ve Maninger, 2011; Sadaf ve diğerleri, 2012). Fakat yapılan çalışmalar göstermektedir ki, öğretmen adayları sınıflarına teknolojiyi entegre etme konusunda kendilerini hala yeterli hissetmemektedir (Ottenbreit-Leftwich, Glazewski, Newby ve Ertmer, 2010; Tondeur ve diğerleri, 2012). Bu noktada öğretmen adaylarının BiT'i eğitimde kullanma yeterliklerine sahip olup olmadığının sorgulanması ve geleceğe yönelik planlamaların yapılması gereklidir.

BiT yeterliklerini ölçme yolları yıllardır araştırmacılar tarafindan farklı biçimde ele alınmıştır (Tondeur ve diğerleri, 2017). Öğretmen adaylarının Bіт yeterliklerini ölçmeye yönelik alan yazında farklı ölçme araçlarının yer aldığı ve bu ölçme araçlarında BіT yeterliklerinin farklı açılardan ele alındığı görülmektedir. Bazı ölçme araçları BiT'in dosya denetimi, internet ve ağ gibi teknik olarak kullanım yeterliklerine odaklanırken (Poelmans, Truyen, Stockman, 2012), bazıları daha farklı bir kavramsal çerçeve çizerek bilgi işleme, iletişim ve etik gibi temaları (Lee, Teo, Chai, Choy, Tan ve Seah, 2007); bazıları ulusal ve uluslararası kuruluşların BiT yeterlik tanımlarından yola çıkarken (Şad, Nalcacı, 2015; Caluza ve diğerleri, 2017), bazılarının da performans değerlendirmeye odaklandıkları (Aesaert ve diğerleri, 2015) görülmektedir. Ayrıca son yıllarda Teknoloji Pedagoji ve Alan Bilgisini (TPAB) kapsayan ölçme araçlarına da rastlanmaktadır (Fisser, Voogt, Tondeur ve Van Braak, 2015; Sang, Tondeur, Chai ve Dong, 2014). Fakat genel olarak birçok çalışmada yapı geçerliliği zorlukları ile ilgili problemler yaşandığı görülmektedir (Tondeur ve diğerleri, 2017). Öğretmen adaylarının BIT'i etkin bir biçimde sınıfa entegre etmede deneyimsizlik hissettikleri ifade edilmektedir (Kay, 2006; Ottenbreit-Leftwich ve diğerleri, 2010). Bu konunun üstesinden gelmek için, birçok araştırmacı halen öğretmen adaylarının BiT entegrasyonunda önemli yere sahip olan BIT yeterliklerinin gelişimi ile ilgili bir dizi sorunu çözebilecek çeşitli alternatifleri incelemektedir (Tondeur ve diğerleri, 2012). Fakat bunun için Bї kullanımına yönelik etkili ve yapı geçerliği şeffaf bir şekilde ortaya koyulmuş bir ölçme aracına intiyaç bulunmaktadır. 
Bu amaçla geliştirilmiş ölçme araçlarından biri olan ve bu makaleye konu olan "Öğretmen Adayı Bilgi ve İletişim Teknoloji Yeterlikleri" adlı ölçme aracı Tondeur ve diğerleri (2017) tarafindan öğretmen adaylarının eğitimde BIT yeterliklerini ölçmek için geliştirilmiştir. Ölçek maddelerinin oluşturulmasında uzmanlardan yardım alınarak kapsamlı alan yazın incelemesi yapılmış ve çeşitli ülkelerin (İngiltere, Çin, Amerika, Belçika gibi) ve kuruluşların (UNESCO, Comman Europan Framework, Digital European Literacy gibi, Tondeur ve diğerleri, 2017, s. 472) yeterlik tanımlarından yararlanılmıştr. Ölçek maddelerinin yazım sürecinde belirli katılımcı gruplarını içeren farklı araştırma aşamaları planlanmıştır. İlk aşamada BIT yeterlik çerçeveleri kapsamında maddelerin oluşmasını yardımcı olmak için analizler gerçekleştirilmiştir. İkinci aşamada içlerinde ilköğretim öğretmenlerinin, öğretmen yetiştiren eğiticilerin, Bї koordinatörlerinin ve araştrrmacıların yer aldığı on beş paydaş ile maddeler değerlendirilmiştir. Bu aşama madde sayısı on dokuza inene kadar ortak öğelerin belirlenmesi, maddelerin düzenlemesi ve ilgili öğelerin tanımlanması şeklinde devam etmiştir. On dokuz madde olarak yapılandırılan ölçek 931 öğretmen adayına uygulanmıştı. Yapı geçerliği çalışmalarının sonucunda ölçeğin 'BiT kullanımında öğrenci öğrenme yetkinliklerini kolaylaştırmak için BiT kullanma becerisi (ICTC-PU)' ve 'BiT’ kendi öğretim amaçları için yönetme yeteneği (ICTC-ID)' olmak üzere iki yapıda doğrulandığı görülmüştür. Bu iki yapı Kennisnet (2012) ve ENW AUGent (2013) tarafindan geliştirilen deneysel tipolojilere benzemektedir. Ayrıca bu iki kategori Van Braak, Tondeur ve Valcke (2004) tarafindan hizmet içi öğretmenler için betimlenen destekleyici Bіт ve sınıf için BiT kullanımı kategorileri ile uyuşmaktadır. Araştırmada ölçeğin iki yapısı arasında makul ve pozitif yönlü bir ilişki bulunmuştur. Her iki BiT yeterliliği arasındaki bu ilişki, BiT'in destekleyici kullanımının BiT kullanımında önemli bir belirleyici olduğunu öne süren Sang, Valcke, van Braak ve Tondeur (2010) çalışmalarında da vurgulanmaktadır. Tüm analizler sonucunda ondokuz madde ve iki faktörden oluşan 'Öğretmen Adaylarının Bilgi ve illetişim Teknoloji Yeterlikleri' ölçeği ortaya koyulmuştur.

BIT deneyimlerinin kalitesi ve miktarı öğretmen adaylarının BiT yeterliklerini geliştirmek için olmazsa olmaz bir faktördür (Ottenbreit-Leftwich ve diğerleri, 2010). Değişen iş güçü ve 21. Yüzyıl yeterliklerinin okul sistemlerine yansıması göz önünde bulundurulduğunda ise öğretmenlerin BIT yeterlikleri ile donatılmış olarak mezun olmaları önemli sayılabilir. Çünkü, teknolojiyi kullanan bir öğretmenin gözlemlenmesi, gelecekte teknolojinin sınıflara entegrasyonu için önemli bir motivasyon kaynağıdır (Kaufman, 2015). Bu açıdan düşünüldüğünde söz edilen ölçek öğretmen adaylarının eğitimde BIT kullanım yeterliklerinin ölçülmesi ve öğretmen eğitmenlerinin profesyonelleşmesine veri sağlaması için kullanılabilir (Tondeur ve diğerleri, 2017).). Ayrıca bu ölçme aracı araştırmacılara potansiyel olarak öğretmen adaylarının BiT yeterliklerini daha şeffaf bir şekilde anlamalarına yardımcı olacak ve öğretmen yetiştiren eğitim kurumlarına BiT'in eğitime entegre edilmesinde intiyaç olan bilginin temini kolaylaşttracaktr (Tondeur ve diğerleri, 2017). Bu noktadan hareketler bu çalışmada, Tondeur ve diğerleri (2017) tarafindan geliştirilen Öğretmen Adayı Bilgi ve İletişim Teknoloji Yeterlikleri Ölçeğinin Türkçeye uyarlama çalışmalarına ve çeşitli değişkenlere (cinsiyet, sınıf ve yaş) göre öğretmen adaylarının BiT kullanma yeterliklerinin incelenmesine yer verilmiştir

\section{Yöntem}

Araştırma kapsamında ölçek uyarlama çalışması yapılmış ve elde edilen ölçek öğretmen adaylarına uygulanarak çeşitli değişkenlere göre analiz edilmiştir.

\section{Çalışma Grubu}

Araştırmanın örneklemini Türkiye'de yer alan beş farklı Eğitim Fakültesi'nde (Tablo 1) öğrenim görmekte olan 242'si (\%73) kadın ve 89'u (\%27) erkek olmak üzere 331 öğrenci oluşturmaktadır (Tablo 2). Öğrencilerin yaş aralıkları 20-25 arasından değişirken (Tablo 3), lisans öğrenimine devam eden 133, mezun durumda olan 198 kattlımcı çalışma grubunda yer almaktadır (Tablo 4).

Tablo 1. Öğrenim görülen/görülmekte olan üniversiteye göre dağılım.

\begin{tabular}{lcc}
\hline & Sıklık & Yüzde \\
\hline Ankara Üniversitesi & 149 & 45,0 \\
Dumlupınar Üniversitesi & 55 & 16,6 \\
Gazi Üniversitesi & 33 & 10,0 \\
Kastamonu Üniversitesi & 38 & 11,5 \\
Yüzüncü Yıl Üniversitesi & 56 & 16,9 \\
Toplam & 331 & 100,0 \\
\hline
\end{tabular}


Tablo 2. Cinsiyete göre dağılım.

\begin{tabular}{lcc}
\hline & Sıklık & Yüzde \\
\hline Erkek & 89 & 26,9 \\
Kadın & 242 & 73,1 \\
Toplam & 331 & 100,0 \\
\hline
\end{tabular}

Tablo 3.Yaşa göre dağılım.

\begin{tabular}{lcc}
\hline & Sıklık & Yüzde \\
\hline 20 & 6 & 1,8 \\
21 & 77 & 23,3 \\
22 & 89 & 26,9 \\
23 & 54 & 16,3 \\
24 & 27 & 8,2 \\
+24 & 78 & 23,6 \\
Toplam & 331 & 100,0 \\
\hline
\end{tabular}

Tablo 4. Mezuniyet durumuna göre dağılım.

\begin{tabular}{lll}
\hline & Sıklık & Yüzde \\
\hline Öğrenci & 133 & 40,2 \\
Mezun & 198 & 59,8 \\
Toplam & 331 & 100,0 \\
\hline
\end{tabular}

\section{Veri Toplama Aracı}

Veri toplama aracı olarak Tondeur ve arkadaşları (2017) tarafindan geliştirilen ve öğretmen adaylarının eğitimde BiT kullanımı yeterlik algılarını belirlemeye yönelik 5'li Likert tipte (1:Kesinlikle Katılmıyorum-5:Kesinlikle Katlıyorum) Öğretmen Adayı Bilgi ve İletişim Teknoloji Yeterlikleri Ölçeği Türkçe'ye uyarlanarak kullanılmıştır. Ölçek, 11 maddesi "öğretmen adayının öğrencilerin bilişim teknolojilerini kullanımını destekleme öz yeterliği algısını" (BiTY-ÖK), 8 maddesi ise "bilişim teknolojilerini öğretim tasarımında kullanma öz yeterliği algısını" (BiTY-ÖT) ölçmeye yönelik olmak iki faktör altında toplam 19 maddeden oluşmuştur. Ölçeğin uyarlanmasına başlamadan önce Tondeur ve diğerlerinden (2017) ölçek uyarlama izni alınmıştr. Ölçek maddeleri, İngilizce dilini iyi derecede kullanan, her iki kültüre de aşina ve ikisi eğitimde BiT entegrasyonu konu alanında yeterliliğe sahip uzmanlar ( 5 kişi) tarafindan Türkçe'ye çevrilmiştir. Ayrı ayrı çevirisi yapılan ölçeğin, farklılaşan yönlerinin belirlenmesine yönelik olarak çapraz kontroller gerçekleştirilmiş ve ortak çevirilerde uzlaşmaya varılmıştır. Ayrıca, ölçeğin Türkçe metni bir Türk dili uzmanına inceletilerek Türkçe yazım ve anlam bütünlüğü açısından uygunluğunun kontrolü yapılmıştr. Ardından ortaya koyulan Türkçe form, her iki dile hakim bir uzman tarafindan yeniden İngilizce'ye çevrilmiş ve orijinal versiyonu ile karşılaştrılarak kontrolleri sağlamıştır. Ölçeğin kullanışlılığını değerlendirmek için ölçme aracı 15 öğretmen adayına uygulanmış ve düzeltme gerektiren bir durum görülmemiştir. Çevirisi tamamlanan ölçek, katılımcıların ulaşılabilirlik durumuna göre çevrimiçi ve basılı olarak uygulanmıştır. Katılımcıların tüm maddeleri doldurması zorunlu olduğu için örneklem kaynaklı herhangi bir veri kaybı olmamıştr.

Ölçek, katılımcılara ulaşılabilirlik durumlarına göre çevrim içi veya basılı olarak uygulanmıştı. Katılımcıların ( $n=331$ ) tüm maddeleri doldurması zorunlu olduğu için kayıp veriye veri setinde rastlanmamıştır. Maddelere ilişkin çarpıklık ve basıklık katsayılarının -1/+1 aralı̆̆ında değer aldığı belirlenmiş ve dağılımların normalliği varsayımına gidilmiştir. Betimsel bulgular için her bir faktöre ilişkin ortalama puanlar hesaplanmıştr. Ayrıca cinsiyet ve sınıf düzeyine göre anlamlı bir farklııı olup olmadığının testi için tek yönlü varyans analizi (ANOVA) yapılmıştır.

\section{Bulgular}

Bu bölümde Öğretmen Adayı Bilgi ve İletişim Teknoloji Yeterlikleri Ölçeğinin uyarlama sonuçlarına ve çeşitli değişkenlere (cinsiyet, yaş ve öğrenim durumuna) göre öğretmen adaylarının BiT kullanma yeterliklerini inceleme sonuçlarına yer verilmiştir.

\section{Öğretmen Adayı Bilgi ve İletişim Teknoloji Yeterlikleri Ölçeğinin Uyarlama Sonuçları}

Doğrulayıcı Faktör Analizi (DFA) standartlaştırılmış sonuçları (Şekil 1) incelendiğinde orijinal ölçektekine benzer olarak öğretmen adaylarının gelecekte, öğrencilerini bilgi ve iletişim teknolojileri kullanmada destekleyebilme öz yeterliği 
(BITY-ÖK) ve gelecekte bilgi ve iletişim teknolojilerini öğretim tasarımı için kullanma öz yeterliği (BiT-ÖT) olarak ayrılan iki faktörlü yapının doğrulandığı ve faktörler arasında yüksek ve anlamlı $(r=0.80, p<0.001)$ bir ilişkinin olduğu görülmektedir. Tondeur ve diğerleri de (2017) orijinal ölçek için bu iki faktör arasında yüksek ve anlamlı $(r=0.68, p<0.001)$ bir ilişki bulmuşlardır. Diğer taraftan maddelere ait regresyon katsayılarına bakıldığında 0.58 ve 0.85 aralığında değerler aldığı (Şekil 1) ve tamamının anlamlı ( $p<0.001)$ olduğu görülmüştür.

Modele ait düzeltme indislerine bakıldığında 1. madde ile 2. madde hata varyansları arasında model uyumunu iyileştirecek düzeyde bir ilişki olduğu görülmüş; maddeler incelendiğinde maddeler arasında bir anlam tekrarının oluşmadığı görülerek her iki madde de modelde tutularak hata varyansları arasındaki ilişki modele dahil edilmiştir. Benzeri bir durumun 3. ve 4. maddeler arasında da olduğu görülmüş; ancak iki maddenin anlam örtüşsmesine sahip olduğu görülerek madde tekrarına düşmemek için yük değeri nispeten düşük olan 3. madde ölçekten çıkarılmıştır.

Model uyumu incelendiğinde 11. ve 13. maddelerin model uyumunu düşürdüğü gözlenerek maddelerin kuramsal yapısı incelenmiş ve ilgili faktörlerin kuramsal temelinden ayrışttkları değerlendirilerek maddeler ölçekten çıkarılmışlardır. Diğer taraftan orijinal ölçekte 15. ve 16. maddeler arasında var olan ilişki mevcut örneklemde görülmemiştir. Bir modelin uyum indeksleri incelendiğinde CMIN/DF değerinin 1-3 arasında değer alması (Camines ve Mlcver, 1981), ve RMSEA değerinin ise .008'den düşük olması kabul edilebilir uyumun (Browne ve Cudeck, 1993) göstergesidir. Ayrıca, NFI değerinin (Bentler ve Bonett, 1980), RFI değerinin (Bollen, 1986) ve CFI değerinin (Bentler, 1990) 0.9'dan yüksek olması ise iyi uyumu göstermektedir. Araşttrmadaki modelin uyum indeksleri incelendiğinde ise değerlerin istenilen aralıklarda olduğu belirlenmiştir (CMIN/DF=2.445; NFI=0.921; RFI=0.907; CFI=0.952; RMSEA=0.066).

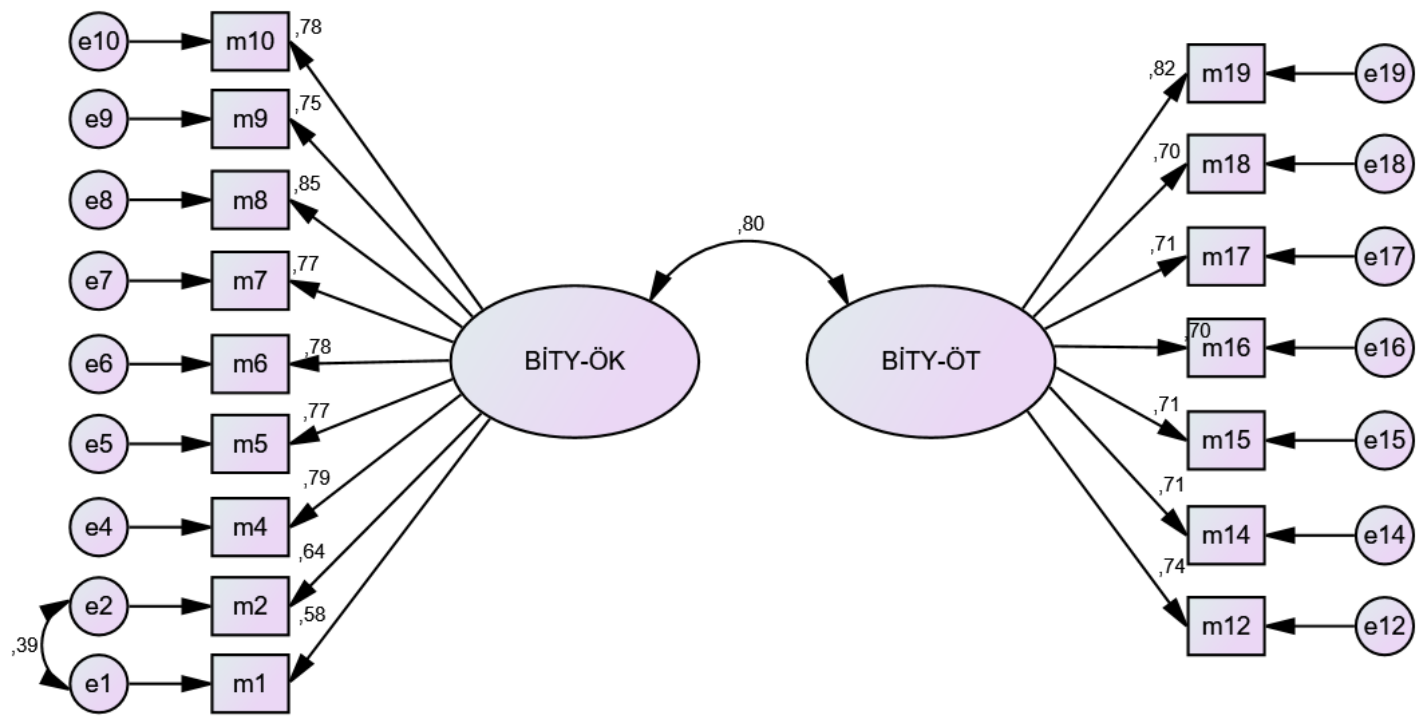

\section{Şekil 1. DFA Modeli Standartlaştırılmış Sonuçlar (Regresyon ve Korelasyon Katsayıları).}

Faktörlere ait iç tutarlılığı değerlendirmek üzere her bir faktör için Cronbach alfa katsayısı hesaplanmış ve BITY-ÖK alt boyutu için 0.919, Віт-ÖT alt boyutu için ise 0.884 bulunmuştur. Bu katsayılara göre ölçeğin iç tutarlılığının yüksek olduğu değerlendirmesine gidilmiştir. Faktörlere ilişkin güvenilirlik incelemesi ayrıca karma güvenilirlik katsayısı hesaplanarak da (BITY-ÖK için 0.921 ve BIT-ÖT için 0.873) teyit edilmiştir.

\section{Çeşitli Değişkenlere Göre Öğretmen Adaylarının BiT Kullanma Yeterliklerinin İncelenmesi}

Betimleyici bulgular incelendiğinde, BITY-ÖK için ortalamanın; kadınlarda 3.93, erkeklerde 3.91 olduğu tespit edilmiş ancak aradaki fark anlamlı görülmemiştir (Tablo 5).

Tablo 5. BітY-ÖK cinsiyete göre ortalama karşılaştırması.

\begin{tabular}{|c|c|c|c|c|c|c|c|c|c|}
\hline & $\mathrm{N}$ & Ort & SS & & Kareler Toplamı & sd & Kareler Ort. & $\mathrm{F}$ & Anlamlılık \\
\hline Erkek & 89 & 3,93 & 0,78 & Gruplar arası & 0,01 & 1 & 0,01 & 0,03 & 0,87 \\
\hline Kadın & 242 & 3,91 & 0,69 & Grup içi & 169,72 & 329 & 0,52 & & \\
\hline Total & 331 & 3,92 & 0,72 & Toplam & 169,74 & 330 & & & \\
\hline
\end{tabular}

BITY-ÖK ortalaması lisans öğrenimine devam eden grupta 3.96 mezun grupta 3.88 bulunmuş; ancak bu fark da an- 
lamlı görülmemiştir (Tablo 6).

Tablo 6. BiTY-ÖK öğrenim durumuna göre ortalama karşılaştırması.

\begin{tabular}{|c|c|c|c|c|c|c|c|c|c|}
\hline & $\mathrm{N}$ & Ort & SS & & Kareler Toplamı & $\mathrm{sd}$ & Kareler Ort. & $\mathrm{F}$ & Anlamlılık \\
\hline 4.Sinıf & 133 & 3,97 & 0,66 & Gruplar arası & 0,52 & 1 & 0,52 & 1,00 & 0,32 \\
\hline Mezun & 198 & 3,89 & 0,75 & Grup içi & 169,22 & 329 & 0,51 & & \\
\hline Total & 331 & 3,92 & 0,72 & Toplam & 169,74 & 330 & & & \\
\hline
\end{tabular}

Віт-ÖТ ortalaması tüm gruplarda; hem kadınlarda hem de erkeklerde ve hem öğrenimine devam edenlerde hem de öğretmenlik formasyon eğitimine devam edenlerde 3.90 bulunmuştur. Diğer taraftan katılımcıların yaş dağıımı ile BITY-ÖK ve BIT-ÖT yeterlik algıları arasındaki ilişki için Pearson korelasyon katsayısına bakılmış ve anlamlı bir ilişki görülmemiştir (BITY-ÖK için $r=0.056 ; p>0.05$ ve BіT-ÖT için $r=0.061 ; p>0.05$ ).

\section{Sonuç ve Öneriler}

21. yüzyıl öğrenci özelliklerine paralel olarak öğretmen adaylarının yeterlikleri çeşitli uluslararası kuruluşlar ve Milli Eğitim Bakanlığı'nın odağında yer almakta ve BiT'in bu yeterlikler arasında önemsendiği görülmektedir. Öğretmen adaylarının BiT yeterliklerini ölçmeye yönelik alan yazında farklı ölçme araçlarının yer aldığı görülmekle birlikte, 21. yüzyıl becerileri ve öğretim tasarımı boyutunu kapsayan Türkçe ölçeklerin yer almadığı görülmektedir. Bu çalışmada da bu noktadan hareketle, Tondeur ve arkadaşları (2017) tarafindan geliştirilen 21. yüzyıl Bï yeterlikleri ölçeğinin Türkçe'ye uyarlama çalışması gerçekleştirilmiştir. Ayrıca, uyarlanan ölçek çeşitli değişkenler ile karşılaştrılmak üzere analiz edilmiştir.

Tondeur ve arkadaşları (2017) tarafindan geliştirilen 21. yüzyıl BiT yeterlikleri ölçeğini Türkçe'ye uyarlamayı amaçlayan çalışmada doğrulayıcı faktör analizi sonucuna ölçeğin iki faktörlü yapıya sahip olduğu doğrulanmış ve faktörler arasında yüksek ve anlamlı bir korelasyon bulunmuştur. Diğer taraftan maddelere ait regresyon katsayılarının yüksek düzeyde ve tamamının anlamlı olduğu belirlenmiştir. Ölçekte yer alan maddelerde modifikasyona gidilmiş, üç madde ölçekten çıkarılmıştır. Modelin veriler üzerindeki uyumu ve ölçeğin iç tutarlıı̆ı̆ını gösteren Cronbach Alfa katsayısının ölçeğin bütünü ve faktörleri için yüksek düzeyde olduğu görülmüştür. Bu sonuçlar orijinal ölçekten elde edilen sonuçları teyit etmektedir.

Betimsel bulgular incelendiğinde öğretmen adaylarının BITY-ÖK ve ВIT-ÖT alt faktörlerine ilişkin ortalama puanlarının yüksek düzeyde olduğu belirlenmiştir. Bu sonuç, katılımcıların kendilerini eğitimde BiT kullanımı konusunda yeterli gördüklerini göstermektedir. Cinsiyet, sınıf ve yaş düzeyinin BiT yeterlikleri üzerindeki etkisi incelendiğinde ise anlamlı bir sonuca ulaşılamamıştır. Benzer şekilde, Yusuf ve Baloğun (2011) ve Şad ve Nalçacı'nın (2015) çalışmalarında da cinsiyet ile, Danner ve Pessu'nun (2013) çalışmasında sınıf düzeylerine göre öğretmen adaylarının BiT yeterlikleri arasında farklılık görülmemiştir.

Günümüz öğrencilerinden ezber bilgiyi alan ve tüketenden ziyade yaratıcı, meraklı, keşfetmeye ve üretmeye hazır, bilgi ve iletişim teknolojileri konusunda okur-yazar, lider, girişimci ve yönlendirici bireyler olmaları beklenmektedir (Karademir, 2018). Günümüz öğretmenlerinden BiT'i sınıflarında etkili biçimde kullanmaları ve öğrencilerin 21. yüzyıl öğrenme becerilerini desteklemesi beklenmektedir. Öğretmen eğitiminin sınıflarda teknolojiyi entegre etme konusunda yeterliliğe sahip olacak biçimde planlanması ve BiT yeterliklerinin ölçülmesi BiT entegrasyonu sürecinde önemli görülmektedir. Teknoloji yoğun öğrenme ortamlarında öğreticinin BiT yeterliklerinin ölçülmesi önerilmektedir (Elstad ve Christophersen, 2017).

Uyarlanan ölçme aracının orijinal ölçeğe benzer bulgulara sahip olduğu ve öğretmen adaylarının BIT yeterliklerini ölçme amacını karşılayabilecek bir ölçme aracı olduğu düşünülmektedir. Bu çalışma yalnızca ölçek uyarlama ve sınırlı sayıda değiş̧kene göre inceleme yapmaya yöneliktir. illerleyen çalışmalarda, araştırmacılara, ölçeği kullanarak öğretmen adaylarının BiT yeterliklerini etkileyen yordayıcıları tespit etmeye yönelik çalışmalar yapması önerilmektedir. Ayrıca ölçek öğretmen adaylarının kendilerini değerlendirmeleri için de kullanılabilir. BiT yeterliliklerinin etkilendiği bireysel ve bağlamsal faktörler (Almerich, Orellana, Suárez-Rodríguez ve Díaz-García, 2016) üzerine çalışmalar da yürütülebilir.

\section{Kaynakça}

Aesaert, K., Van Nijlen, D., Vanderlinde, R., Tondeur, J., Devlieger, I., \& Van Braak, J. (2015). The contribution of pupil, classroom and school level characteristics to primary school pupils' ICT competences: A performance-based approach. Computers \& Education, 87, 55-69.

| Kastamonu Eğitim Dergisi, 27(4), 2019| 
Anderson, S. E., Groulx, J. G., \& Maninger, R. M. (2011). Relationships among preservice teachers' technology-related abilities, beliefs and intentions to use technology in their future classrooms. Journal of Educational Computing Research, 45(3), 321-338.

ENW AUGent (2013). The flemish ICT development profile for teacher educators. Erişim adresi: https://velov.files.wordpress.com/2012/02/ velov_bro_en_111206.pdf

Binkley, M., Erstad, O., Hermna, J., Raizen, S., Ripley, M., Miller-Ricci, M. \& Rumble, M. (2012). Defining Twenty-First Century Skills. In Griffin, P., Care, E., ve McGaw, B. (Eds) Assessment and Teaching of 21st Century Skills (17-66), Dordrecht, Springer. Erişim Adresi: https:// link.springer.com /chapter/ 10.1007\%2F978-94-007-2324-5_2

Caluza, L.J., Verecio, R.L., Funcion, D.G., Quisumbing, L.A., Gorardo, M.A., Laurente, M.L.P., Vinco, J.C., \& Marmite, V. ( 2017). An assessment of ICT competencies of public school teachers: Basis for community extension program. IOSR Journal Of Humanities And Social Science. 22(3), 01-13. Erişim adresi: http://www.iosrjournals.org/iosr-jhss/papers/Vol.\%2022\%20lssue3/Version-4/A2203040113.pdf

Durak, H. \& Seferoğlu, S.S. (2017). Öğretmenlerin teknoloji kullanım yeterliklerinde etkili olan faktörlerle ilgili bir inceleme. H.F.Odabaşı, B. Akkoyunlu ve A. İşman (Ed). Eğitim teknolojileri okumaları 2017 (Bölüm 29, 537-556). TOJET ve Sakarya Üniversitesi, Adapazarı.

Fadel, C. \& Center for Curriculum Redesign (2015). Redesigning the curriculum for a 21st century education (white paper). Erişim Adresi: https://curriculumredesign.org/wp-content/uploads/CCR-FoundationalPaper-Updated-Jan2016.pdf

Fisser, P., Voogt, J., Tondeur, J., \& van Braak, J. (2015). Measuring and assessing TPACK (Technological, Pedagogical, and Content Knowledge). Encyclopaedia of Educational Technology, 2, 490-493.

Göksun, D. O. \& Kurt, A.A. (2017). Öğretmen adaylarının 21. yy. öğrenen becerileri kullanımları ve 21. yy. öğreten becerileri kullanımları arasındaki ilişki. Eğitim ve Bilim. 42(190), 107-130, Erişim Adresi:http://egitimvebilim.ted.org.tr/index.php/EB/article/view/7089 $/ 2610$

ISTE. (2009). ISTE standards for teachers. Erişim adresi: https://www.iste.org/docs/pdfs/20-14_ISTE_Standards-T_PDF.pdf

ISTE. (2017). ISTE Standards for educators.. Erişim adresi: https://www.iste.org/standards/for-educators

Karademir, T. (2018). Teknolojinin benimsenmesine ekolojik bir yaklaşım: Sürdürülebilir bir dijital öğretim materyali geliştirme ekosistemi (Yayımlanmamış doktora tezi). Ankara Üniversitesi, Eğitim Bilimleri Fakültesi, Ankara.

Kaufman, K. (2015). Information communication technology: Challenges \& some prospects from preservice education to the classroom. Mid-Atlantic Education Review, 2, 1-11.

Kay, R. H. (2006). Evaluating strategies used to incorporate technology into preservice education: A review of the literature. Journal of Research on Technology in Education, 38, 383-408

Keane, W.F. \& Keane, T. (2013). Deep Learning, ICT and 21st Century Skills. Paradox and Possibility, The 6th International Conference on Catholic Educational Leadership, Sydney, Australia. Erişim adresi: https://www.acu.edu.au/_data/assets/pdf_file/0009/576009/Keane,_William_and_Therese_-_Deep_Learning,_ICT_and_21st_Century_Skills.pdf

Kereluik, K., Mishra P., Fahnoe, C. \& Terry, L. (2013). What knowledge is of most worth: teacher knowledge for 21st century learning. Journal of Digital Learning in Teacher Education, 29(4), 127-140. Erişim adresi: https://files.eric.ed.gov/fulltext/EJ1010753.pdf

Kennisnet. (2012). ICT proficiency of teachers. Nederland: Kennisnet.

Lee, C.B., Teo,T., Chai, C.S., Choy, D., Tan, A., \& Seah, J. (2007). Closing the gap: Preservice teachers' perceptions of an ICT based, student centred learning curriculum. In ICT: Providing choices for learners and learning. Proceedings ascilite Singapore 2007. http://www. ascilite.org.au/conferences/singapore07/procs/lee-cb.pdf

Mishra, P. \& Koehler, M. J. (2006). Technological pedagogical content knowledge: A new framework for teacher knowledge. Teachers College Record,108 (6), 1017-1054.

NRC (2011). National Research Council (US) Committee on the Assessment of 21st Century Skills. Washington. ISBN-13: 978-0-309-217903ISBN-10: 0-309-21790-3

Ottenbreit-Leftwich, A., Glazewski, K. D., Newby, T. J., \& Ertmer, P. A. (2010). Teacher value beliefs associated with using technology: Addressing professional and student needs. Computers \& Education, 55, 1321-1335.

P21-Partnership for 21st Century Learning (2016). Framework for 21st Century Learning. Erişim adresi: http://www.p21.org/storage/ documents/docs/P21_framework_0816.pdf

Poelmans, S., Truyen, F.R., \& Stockman, C. ( 2012). ICT skills and computer self-efficacy of higher education students. Proceedings of INTED2012 Conference da sunulan bildiri. 5th-7th March 2012, Valencia, Spain. Erişim adresi: https://lirias.kuleuven.be/bitstream/ 123456789/341696/1/1303.pdf

Saavedra, A.R., \& Opfer, D. (2012). Teaching and learning 21st century skills: Lessons from the learning sciences report. Paper Presented at the Joint AARE/ APERA Conference, Sdney. Erişim Adresi: http://asiasociety.org/files/rand-1012report.pdf

Sadaf, A., Newby, T. J., \& Ertmer, P. A. (2012). Exploring pre-service teachers' beliefs about using Web 2.0 technologies in K-12 classroom. Computers \& Education, 59(3), 937-945.

Sang, G., Tondeur, J., Chai, C. S., \& Dong, Y. (2016). Validation and profile of Chinese pre-service teachers' technological pedagogical content knowledge scale. Asia-Pacific Journal of Teacher Education, 44(1), 49-65.

Sang, G., Valcke, M., van Braak, J., \& Tondeur, J. (2010). Student teachers' thinking processes and ICT integration: Predictors of prospective 
teaching behaviors with educational technology. Computers \& Education, 54, 1, 103-112.

Şad, S.N., Nalcacı, Ö. İ. ( 2015). Öğretmen adaylarının eğitimde bilgi ve iletişim teknolojilerini kullanmaya ilişkin yeterlilik algıları. Mersin Üniversitesi Eğitim Fakültesi Dergisi, 11(1), 177-197.

Tokmak, H.S., Konokman, G.Y., \& Yelken, T.Y. (2013). Mersin üniversitesi okul öncesi öğretmen adaylarının Teknolojik Pedagojik Alan Bilgisi (TPAB) özgüven algılarının incelenmesi. Ahi Evran Üniversitesi Kırşehir Eğitim Fakültesi Dergisi, 14(1), 35-51.

Tondeur, J., Van Braak, J., Sang, G., Voogt, J., Fisser, P., \& Ottenbreit-Leftwich, A. (2012). Preparing preservice teachers to integrate technology in education: a synthesis of qualitative evidence. Computers \& Education, 59, 134-144.

Tondeur, J., Aesaert, K., Pynoo, B., Braak, J., Fraeyman, N., \& Erstad, O. (2017). Developing a validated instrument to measure preservice teachers' ICT competencies: Meeting the demands of the 21st century. British Journal of Educational Technology, 48(2), $462-472$.

UNESCO. (2011). UNESCO ICT competency framework for teachers. Erişim adresi: http://unesdoc.unesco.org/images/0021/002134/213475e.pdf

Wagner, T. (2008).The Global Achievement Gap: Why even our best schools don't teach the new survival skills our children need-and what we can do about it. New York, NY: Basic Books

\section{Öğretmen Adayı BiтT Yeterlikleri Ölçeği Maddeleri}

Bilgi ve Illetişim Teknolojileri Kullanımını Destekleme Öz Yeterliği (BiTY-ÖK)

- m1. BiT'i olumlu bir şekilde kullanmaları için öğrencileri motive edebilirim.

- m2. Biт’i eleştirel bir şekilde kullanmaları için öğrencileri güdüleyebilirim.

- m3. Öğrencilere, BiT aracılığıyla bilgi/beceri alıştırması yapmaları konusunda faaliyetler sunabilirim. (ölçekten çıkarıldı)

- m4. Öğrencilere, BíT ile öğrenmeleri için belirli konularda etkinlikler sunabilirim.

- m5. Öğrencilere, BiT aracılığıyla fikirlerini yaratıcı bir biçimde ifade etmeleri için firsatlar sunabilirim.

- m6. Öğrencilere, BiT aracııı̆̆ıla araştırma yapmaları konusunda destek sağlayabilirim.

- m7. Öğrencilere, BiT aracılığıyla bilgiyi işleme ve yönetme konusunda destek sağlayabilirim.

- m8. Öğrencilere, Biт aracılı̆̆ıla bilgi sunma konusunda destek sağlayabilirim.

- m9. Öğrencilere, Biт ile güvenli, sorumlu ve etkili bir biçimde iletişim kurma konusunda destek sağlayabilirim.

- m10. Öğrencilere, BiT ile birlikte çalışma konusunda destek sağlayabilirim.

Bilgi ve İletişim Teknolojilerini Öğretim Tasarımı için Kullanma Öz yeterliği (BiT-ÖT)

- m11. Öğrencilere, BiT’i bilinçli bir biçimde kullanma (ergonomi, fikri mülkiyete saygı gösterme vb.) eğitimi verebilirim. (ölçekten çıkarıldı)

- m12. Віт uygulamalarını belirli bir eğitim ortamına göre seçebilirim.

- m13. BiT uygulamalarını belirli bir eğitim ortamına göre (yeniden) tasarlayabilirim. (ölçekten çıkarıldı)

- m14. Biт'i, öğrenme ve öğretimi zenginleştirmek için kullanabilirim.

- m15. Öğrencilerin öğrenme gelişimini dijital bir yolla takip edebilirim.

- m16. Öğrencileri BiT yardımıyla değerlendirebilirim.

- m17. Biт'i, öğrencilerle uygun bir biçimde iletişim kurmak için kullanabilirim.

- m18. Mevcut olanaklarla bir öğrenme ortamı tasarlayabilirim.

- m19. Віт uygulamalarını, etkili bir biçimde öğrenme ortamı oluşturmak için seçebilirim (örneğin, grup büyüklüğüne göre). 